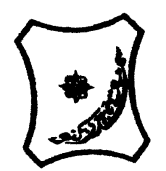

Bayero Journal of Pure and Applied Sciences, 9(1): 206 - 212

Received: April, 2016

Accepted: June, 2016

ISSN $2006-6996$

\title{
SYNTHESIS, CHARACTERIZATION, ANTIMICROBIAL AND ANTIOXIDANT STUDIES OF 2-[(2-HYDROXYPHENYL) METHYLIDENE] HYDRAZINE-1- CARBOXAMIDE AND ITS METAL (II) COMPLEXES
}

\author{
Sani, U. and Baba M. A. \\ Department of Pure and Industrial Chemistry, Bayero University, Kano, P. M. B. 3011 Kano Nigeria \\ Email: sumar.chm@buk.edu.ng, nababaagwa@yahoo.com, alawiyyababamusa@yahoo.com
}

\section{ABSTRACT}

2-\{(2-hydroxyphenyl) methylidene\}hydrazine-1-carboxamide has been synthesized from salicylaldehyde and semicarbazide. Its metal (II) complexes were prepared from Cu(II) and Zn(II) chlorides respectively. The compounds were characterized on the basis of solubility, melting point/decomposition temperature, magnetic susceptibility, molar conductance, UV-visible sphectrophotometric data, and FT-IR. From the IR spectrum of 2-\{(2-hydroxyphenyl) methylidene\} hydrazine-1-carboxamide a band at $1687 \mathrm{~cm}^{-1}$ was observed and assigned to $-C=N$, while for the complexes, it shifted to $1683-1686 \mathrm{~cm}^{-1}$.The complexes recorded high decomposition temperature suggesting that the compounds are stable. Conductivity measurement revealed that the complexes

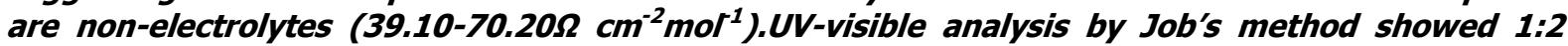
metal ligand ratio. The compounds were tested against Staphylococcus aureus, E. coli, Klebsiella pneumonae bacterial isolates as well as Mucor species and A. fumigatus fungal isolates by disc diffusion method. The result showed that some of the compounds are active while some are inactive on the isolates. Antioxidant activity test was carried out using 2,2-diphenyl-1picryhydrazyI (DPPH) and the results were analyzed by SPSS 16.0 Software. The IC 50 showed that the ligand and copper (II) complexes possess antioxidant property while zinc (II) complex does not.

Keywords: Antimicrobial, Antioxidant, Characterization, Ligand, Synthesis

\section{INTRODUCTION}

Schiff bases represent one of the most employed classes of ligands in coordination chemistry due to their convenient synthetic preparation and high versatility. These aspects influence their ability to form stable complexes with majority of transitional metal ions. Significant number of Schiff bases and their complexes have been studied, due to their interesting properties which include ability to reversibly bind oxygen (Cotton, 2006), catalytic activity in hydrogenation of olefins (Youseef, 2008), transfer of an amino group (Katsuki, 1995), photochromic properties (Chandra 2002) and ability to form complexes with some toxic metals (Chandra, 2005). Schiff base complexes have been a subject of much interest due to growing applications in the field of catalysis, electrochemistry, bioinorganic, separation processes, metallic deactivators and environmental chemistry (Ziyad et al., 2011).

This paper reports synthesis of 2-\{(2hydroxyphenyl)methylidene hydrazine-1-carboxamide derived from salicyladehyde and semicarbazide, and its Copper (II) and Zinc (II) complexes.

\section{MATERIALS AND METHODS}

Materials and Collection of Sample

All reagents used are of analytical grade and were used without purification. Melting point/decomposition temperature was determined by Melting Point SMP10 Apparatus. IR spectra measurements were recorded using Shimadzu FTIR-8400S Spectrophotometer. Electrical conductivity measurement was carried out using conductivity meter Jenway 4010 model. UVVisible spectral measurement was done on a Perkin Elmer Lambda 35.The magnetic susceptibility of complexes was determined on MBS MKI Magnetic susceptibility balance at $25^{\circ} \mathrm{C}$. The Ligand and its complexes have been tested for antibacterial and antifungal activity against some pathogenic bacteria (S. aurius, E. coli, K. pneumonae) and fungi (Mucor $\mathrm{Sp}, A$. fumigatus) obtained from Aminu Kano Teaching Hospital and identified at the Department of Microbiology Bayero University Kano. Nutrient Agar (NA) and potato Dextrose Agar (PDA) were used as bacterial and fungal media respectively. Antioxidant Activity of the Ligand and the metal complexes was determined using DPPH and the result analyzed by SPSS 16.0 Software.

Preparation of 2-\{(2-hydroxyphenyl) methylidene\}hydrazine-1-carboxamide

Ethanolic solution of semicarbazide $(0.7508 \mathrm{~g}$, $10 \mathrm{mmol})$ and salicylaldehyde $(1.139 \mathrm{ml}, 10 \mathrm{mml})$ were taken in a round bottom flask. Sodium acetate $(0.01 \mathrm{~g})$ was added and the mixture was refluxed at $80^{\circ} \mathrm{C}$ for two hours. On cooling, white ligand was precipitated out. The product was collected by filtration, washed with ethanol and then recrystallized from ethanol and dried in a dessicator over phosphorus pentaoxide for a week (Sulekh et al., 2012). 


\section{Preparation of the Complexes}

Ethanolic solutions of the metal (II) chloride and 2\{(2-hydroxyphenyl) methylidene $\}$ hydrazine-1carboxamide were mixed together with constant stirring. The mixture was refluxed for four hours at $80-85^{\circ} \mathrm{C}$ and later concentrated by evaporation on water bath. The precipitate formed was filtered, washed with ethanol and dried over phosphorus pentaoxide for a week (Sulekh et al., 2012)

Determination of Number of Coordinated Ligand

The number of ligand coordinated to the metal ion was determined using Job's method of continuous variation (Angelici, 1971). 3mmol methanolic solution of the ligand and the metal chlorides were prepared. The following Ligand to Metal salt mixture $(\mathrm{ml}) ; 1: 15$, $3: 13,5: 11,7: 9,9: 7,11: 5,13: 3,15: 5$ were prepared from the ligand solution and each of the metal chlorides solutions respectively. A total volume of $16 \mathrm{ml}$ was maintained (in that order) throughout the process and the mole fraction of the ligand was calculated in each mixture. The solutions of the metal chlorides were scanned (as blank) to find the wavelength of maximum absorption $\left(\lambda_{\max }\right)$ for that particular metal ion (Angelici, 1971). The machine was fixed at $685 \mathrm{~nm}$ and $405 \mathrm{~nm}$ for Copper (II) and Zinc (II) chlorides respectively as $\lambda_{\max }$ (in each case) before taking the absorbance values of each solution mixture. The absorbance values were plotted against mole fraction of the ligand and the average number of coordinated ligand to the metal ion was determined using the relation below:

$$
\bar{n}=\frac{x_{i}}{1-x_{i}}
$$

Where $x_{i}=$ mole fraction at maximum absorbance,

$$
n=
$$

average number of coordinated ligand to metal ion

\section{Antibacterial Activity Test}

The in vitro antibacterial activity of the ligand and the metal complexes were assayed using three bacterial isolates: Staphylococcus aureus, Escherichia coli and Klebsiella pneumonae using disc diffusion method (Sharma et.al, 2009). The suspension of each microorganism was rubbed onto the surface of solidified nutrient agar (N.A) already poured into Petri dishes. Different concentrations $(15,30$ and $60 \mu \mathrm{g} / \mathrm{disc}$ ) of the Schiff base ligand and the metal complexes in DMSO were prepared through serial dilution and placed on the culture media before incubation at $37^{\circ} \mathrm{C}$ for 24 hours. Activities were determined by measuring (in $\mathrm{mm}$ ) the diameter of the zone of inhibition and compared the result with a standard.

\section{Antifungal Activity Test}

The in vitro antifungal activity of the Schiff base ligand and its metal complexes were studied on two fungi namely; Aspergillus fumigatus and Mucor sp. using disc diffusion method. (Sharma et al, 2009). The fungal suspensions were rubbed onto the surface of solidified Potato Dextrose Agar (PDA) already poured into Petri dishes. Different concentrations (15, 30 and $60 \mu \mathrm{g} / \mathrm{disc}$ ) of the Schiff base ligand and the metal complexes in DMSO were prepared through serial dilution and placed on the culture media. This was left to stand at room temperature for about 48 hours. Activities were determined by measuring (in $\mathrm{mm}$ ) the diameter of the zone showing complete inhibition and comparing the result with a standard.

\section{Antioxidant Activity:}

The free radical scavenging activity of the Ligand and its Metal (II) complexes against 2,2-diphenyl-1picrylhydrazine (DPPH) radical was determined according to the method described by Sharma and Bhat (2009). Each sample of stock solution $(1.0 \mathrm{mg} / \mathrm{mL})$ was diluted to final concentration of $1000,500,250,125,62.5,31.3,15.63$ and $7.82 \mu \mathrm{g} / \mathrm{ml}$. A total of $50 \mu \mathrm{m}$ DPPH methanolic solution $(3.8 \mathrm{ml})$ was added to the sample solution $(0.1 \mathrm{ml})$ and allowed to react at room temperature for $30 \mathrm{~min}$ in dark. The absorbance of the mixtures was measured at 517nm. Ascorbic acid and Butylated hydroxytoluene were used as positive controls. Lower absorbance of the reaction mixture indicates higher free radical scavenging activity, and vice versa. Inhibitions of DPPH radical in percent $(1 \%)$ were calculated using the formula:

$$
\frac{A_{\text {blank }}-A_{\text {sample }}}{A_{\text {blank }}} \times 100 \quad \mathrm{I} \%=
$$

Where, $A_{\text {blank }}$ is the absorbance value of the control reaction (containing all reagents except the test compound) and $A_{\text {sample }}$ is the absorbance values of the test compounds. The sample concentration that provides $50 \%$ inhibition ( $\mathrm{IC}_{50}$ ) was determined using SPSS 16.0 software.

\section{RESULTS AND DISCUSSION}

2-\{(2-hydroxyphenyl)methylidene\}hydrazine-1carboxamide was synthesized by condensing salicylaldehyde and semicarbazide as creamy solid with good yield (Table 1). The metal (II) complexes were obtained by refluxing the ligand and the metal (II) chlorides as gray and white solids with sharp decomposition temperatures of $280^{\circ} \mathrm{C}$ and $285^{\circ} \mathrm{C}$ respectively suggesting that the complexes are stable. From the magnetic moment measurements (Table 1), the complexes were found to be diamagnetic Conductivity measurement of the complexes revealed their non electrolytic nature (Gary, 1971) as seen Table 1

Table 1: Physical and some Analytical Data of the Schiff base and the Metal (II) Complexes

\begin{tabular}{ccccccc}
\hline Compounds & $\begin{array}{c}\text { Mol. } \\
\text { Formula }\end{array}$ & Colour & $\begin{array}{c}\% \\
\text { Yield }\end{array}$ & $\begin{array}{c}\text { Melting/ } \\
\text { decomposition } \\
\left.\text { Temperature ( }{ }^{\circ} \mathbf{C}\right)\end{array}$ & $\begin{array}{c}\text { Magnetic } \\
\text { Moment } \\
\text { (BM) }\end{array}$ & $\begin{array}{c}\text { Molar } \\
\text { Conductance } \\
\left(\mathbf{O h m}^{-1} \mathbf{c m}^{\mathbf{2}} \mathbf{m o l}^{-\mathbf{1}} \mathbf{)}\right.\end{array}$ \\
\hline Ligand & $\mathrm{C}_{8} \mathrm{H}_{9} \mathrm{~N}_{3} \mathrm{O}_{9}$ & Creamy & 60 & 234 & - & - \\
{$[\mathrm{CuL}]$} & $\mathrm{C}_{16} \mathrm{H}_{20} \mathrm{CuN}_{6} \mathrm{O}_{6}$ & Grey & 93 & 280 & Dia & 70.2 \\
{$[\mathrm{ZnL}]$} & $\mathrm{C}_{16} \mathrm{H}_{20} \mathrm{~N}_{6} \mathrm{O}_{6} \mathrm{Zn}$ & White & 94 & 285 & Dia & 39.1 \\
\hline
\end{tabular}

$\mathrm{L}=2-\{(2-$ hydroxyphenyl)methylidene $\}$ hydrazine-1-carboxamide 
Solubility analysis showed that the ligand the metal complexes showed different behavior in some common solvents. 2-\{(2hydroxyphenyl)methylidene\}hydrazine-1-carboxamide and its copper (II) as well as zinc (II) complexes are soluble in dimethyl sulphoxide (DMSO) as presented in Table 2. This may be due to the high dielectric constant of that solvent (www.depts.washington.edu 2016).

Table 2: Solubility Test of the Ligand and its Metal (II) Complexes in Water and Some Common Organic Solvents.

\begin{tabular}{ccccccccc}
\hline Compound & $\mathbf{H}_{\mathbf{2}} \mathbf{O}$ & $\mathbf{M e O H}$ & EtOH & Acetone & $\mathbf{C C l}_{\mathbf{4}}$ & Chloroform & DMF & DMSO \\
\hline Ligand & IS & S & IS & SS & IS & IS & IS & S \\
[CuL] & IS & S & IS & SS & IS & IS & IS & S \\
[ZnL] & IS & S & IS & SS & IS & IS & IS & S \\
\hline
\end{tabular}

$\mathrm{L}=2$-[(2-hydroxyphenyl) methylidene]hydrazine-1-carboxamide.

KEY: S=Soluble, SS=Slightly Soluble and IS=Insoluble

FT-IR spectra data (Table 3) of 2-[(2-hydroxyphenyl) methylidene]hydrazine-1-carboxamide show absorption peak at $1687 \mathrm{~cm}^{-1}$ assignable to azomethine and confirms the formation of the ligand (Raman et al,. 2001). This peak shifted to $1683 \mathrm{~cm}^{-1}$ and $1686 \mathrm{~cm}^{-1}$ in the spectra of the complexes, additionally new absorption peaks at $748 \mathrm{~cm}^{-1}$ and
$752 \mathrm{~cm}^{-1}$ assignable to $\mathrm{M}-\mathrm{N}$ bond were observed. Furthermore, $\mathrm{M}-\mathrm{O}$ absorption peaks were recorded at $428 \mathrm{~cm}^{-1}$ and $412 \mathrm{~cm}^{-1}$. Those absorption peak confirm the coordination of the azomethine nitrogen and deprotonation of phenolic $-\mathrm{OH}$ in the formation of the metal (II) complexes (Byeong-Geo et al., 1996).

Table 3: Selected Vibration Frequencies of the Schiff base and the Metal

\begin{tabular}{ccccc}
\hline Compound & $\mathbf{0}(\mathbf{O}-\mathbf{H}) \mathbf{c m}^{\mathbf{- 1}}$ & $\mathbf{0}(\mathbf{C}=\mathbf{N}) \mathbf{c m}^{\mathbf{- 1}}$ & $\mathbf{0}(\mathbf{M}-\mathbf{N}) \mathbf{c m}^{\mathbf{- 1}}$ & $\mathbf{0}(\mathbf{M - O}) \mathbf{c m}^{\mathbf{- 1}}$ \\
\hline Ligand & 3466 & 1687 & & \\
{$[\mathrm{CuL}]$} & & 1683 & 748 & 428 \\
{$[\mathrm{ZnL}]$} & 1686 & 752 & 412 \\
\hline
\end{tabular}

L=2-[(2-hydroxyphenyl) methylidene]hydrazine-1-carboxamide.

Jobs method of continuous variation was used for the estimation of the ligand to metal ratio (Angelici, 1971).The plot of absorbance against mole fraction ligand - metal ion mixture (Fig. 1) in each case at maximum absorbance corresponding to the ligand mole fraction suggest 1:2 metal-ligand ratio in the complexes.

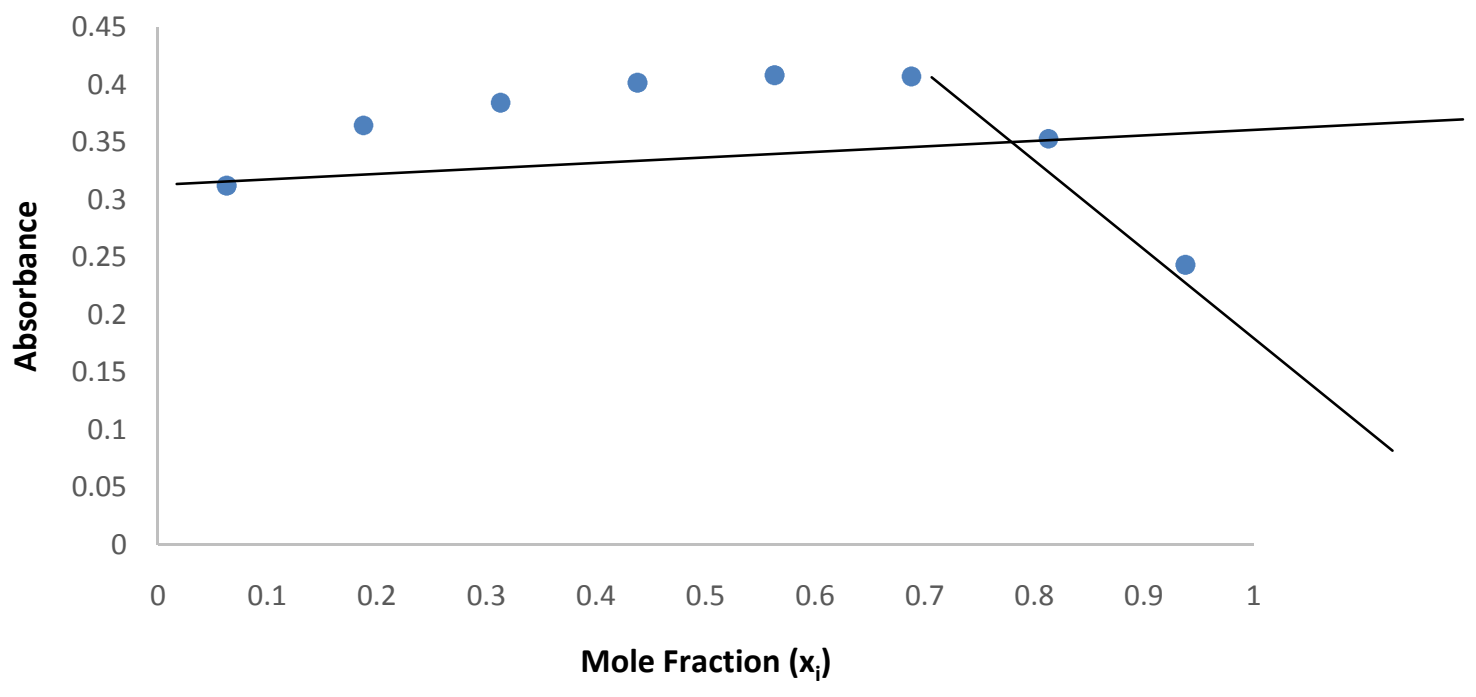

Figure 1: Plot of Absorbance against Mole Fraction Metal - Ligand Mixture

The synthesized compounds were tested for their antibacterial and antifungal activity by measuring the inhibition zone by disc diffusion method with Staphylococcus aureus, Echeria coli and Klebsiella pneumonae at concentrations of 15,30 and $60 \mu \mathrm{g} /$ disc. The results of antibacterial studies of the complexes and the ligand are listed in Table 4 as determined by measuring the zone of inhibition( $\mathrm{mm})$. The result show that the Manganese complex shows highest zone of inhibition $18 \mathrm{~mm}$ against $K$. pneumonae, while the complexes of Nickel and Zinc show poor activity on bacteria ( $E$. coli) and ( $K$. pneumonae).The ligand was also found to be active though its complexes displayed enhanced activity against the tested isolates as chelation tends 
to make the ligand acts as more powerful and potent bactericidal agent (Morad et al., 2007).

The antifungal activity test results (Table 5) indicate that the complexes show an appreciable activity against $A$. fumigatus and Mucor species were more active than the free ligand and can be explained by Overtones concept and Tweedy's chelation theory (Raman et al., 2009). The mode of action of the compounds may involve formation of a hydrogen bond through the azomethine group with the active centers of cell constituent resulting in an interference with normal cell process. (Dharamraj et al,. 2001). Copper complex show the highest activity among all the metal complexes. Clearly the results show that both the ligand and their metal complexes have the capacity of inhibiting growth of the investigated bacteria and fungi to different degree. The inhibition zone of the metal chelates generally is higher than that of the free ligand.

Table 4: Antibacterial Activities of the Ligand and the Complexes

\begin{tabular}{lccccccccc}
\hline Compound & \multicolumn{8}{c}{ Zone of Inhibition $(\mathrm{mm}) /$ Concentration( $\mu \mathrm{g} / \mathrm{disc})$} \\
& \multicolumn{1}{c}{ Staphyloccocus aureus } & \multicolumn{3}{c}{ E. coli } & \multicolumn{3}{c}{ kneumonae } \\
\hline & $\mathbf{1 5}$ & $\mathbf{3 0}$ & $\mathbf{6 0}$ & $\mathbf{1 5}$ & $\mathbf{3 0}$ & $\mathbf{6 0}$ & $\mathbf{1 5}$ & $\mathbf{3 0}$ & $\mathbf{6 0}$ \\
Ligand & 10 & 14 & 17 & 10 & 12 & 15 & 12 & 14 & 17 \\
{$[\mathrm{CuL}]$} & $\mathrm{NZI}$ & 8 & 9 & 10 & 14 & 16 & 9 & 11 & 14 \\
{$[\mathrm{ZnL}]$} & 9 & 10 & 13 & NZI & NZI & NZI & 8 & 10 & 12 \\
\hline
\end{tabular}

$\mathrm{L}=2$-[(2-hydroxyphenyl)methylidene]hydrazine-1-carboxamide.

NZI $=$ No zone of inhibition

Table 5:Antifungal Activities of the ligand and Complexes

\begin{tabular}{|c|c|c|c|c|c|c|}
\hline \multirow[t]{3}{*}{ Compound } & \multicolumn{6}{|c|}{ Zone of Inhibition (mm)/Concentration ( $\mu \mathrm{g} / \mathrm{disc})$} \\
\hline & & cor & & & Fu & \\
\hline & 15 & 30 & 60 & 15 & 30 & 60 \\
\hline Ligand & NZI & NZI & NZI & 7 & 9 & 11 \\
\hline [CuL] & 11 & 15 & 18 & 12 & 16 & 19 \\
\hline$[\mathrm{ZnL}]$ & 9 & 10 & 14 & 8 & 11 & 14 \\
\hline
\end{tabular}

L=2-[(2-hydroxyphenyl) methylidene]hydrazine-1-carboxamide.

The result for the antioxidant activity of the ligand and metal (II) complexes is presented in Table 6.The DPPH scavenging assay of test compounds was measured spectrophotometrically at $517 \mathrm{~nm}$. The $\mathrm{IC}_{50}$ values showed that the ligand and the copper (II) complex exhibit scavenging activity against DPPH free radical. It is obvious that the Zinc metal showed no antioxidant scavenging activity which may be related to the positive charged density. Structure activity relationship studies showed that the antioxidant activity of the ligand could be attributed to electron or hydrogen donating ability of the DPPH and $\mathrm{OH}$ so that they become less stable molecules. The $\mathrm{IC}_{50}$ values were compared with that of $\mathrm{BHT}$ and vitamin $\mathrm{C}$ standards as shown in Fig. 2 and Fig. 3 respectively.

Table 6: Antioxidant scavenging activities data of the ligand, [CuL] and [ZnL]

\begin{tabular}{|c|c|c|c|c|c|}
\hline Concentration & BHT & Vitamin C & Liganc & [CuL] & {$[\mathbf{Z n L}]$} \\
\hline 250 & 94.47 & 94.61 & 95.06 & 91.33 & 38.25 \\
\hline 100 & 91.86 & 94.16 & 94.83 & 92.09 & 36.12 \\
\hline 50 & 87.07 & 82.34 & 75.81 & 90.74 & 37.41 \\
\hline 25 & 80.21 & 56.73 & 72.53 & 77.00 & 38.24 \\
\hline 10 & 67.68 & 39.11 & 71.81 & 63.16 & 27.24 \\
\hline IC $_{50}$ Values $=$ & $15.33 \mu \mathrm{g} / \mathrm{ml}$ & $15.55 \mathrm{\mu g} / \mathrm{ml}$ & $3.23 \mu \mathrm{g} / \mathrm{ml}$ & $3.21 \mu \mathrm{g} / \mathrm{ml}$ & ml \\
\hline
\end{tabular}




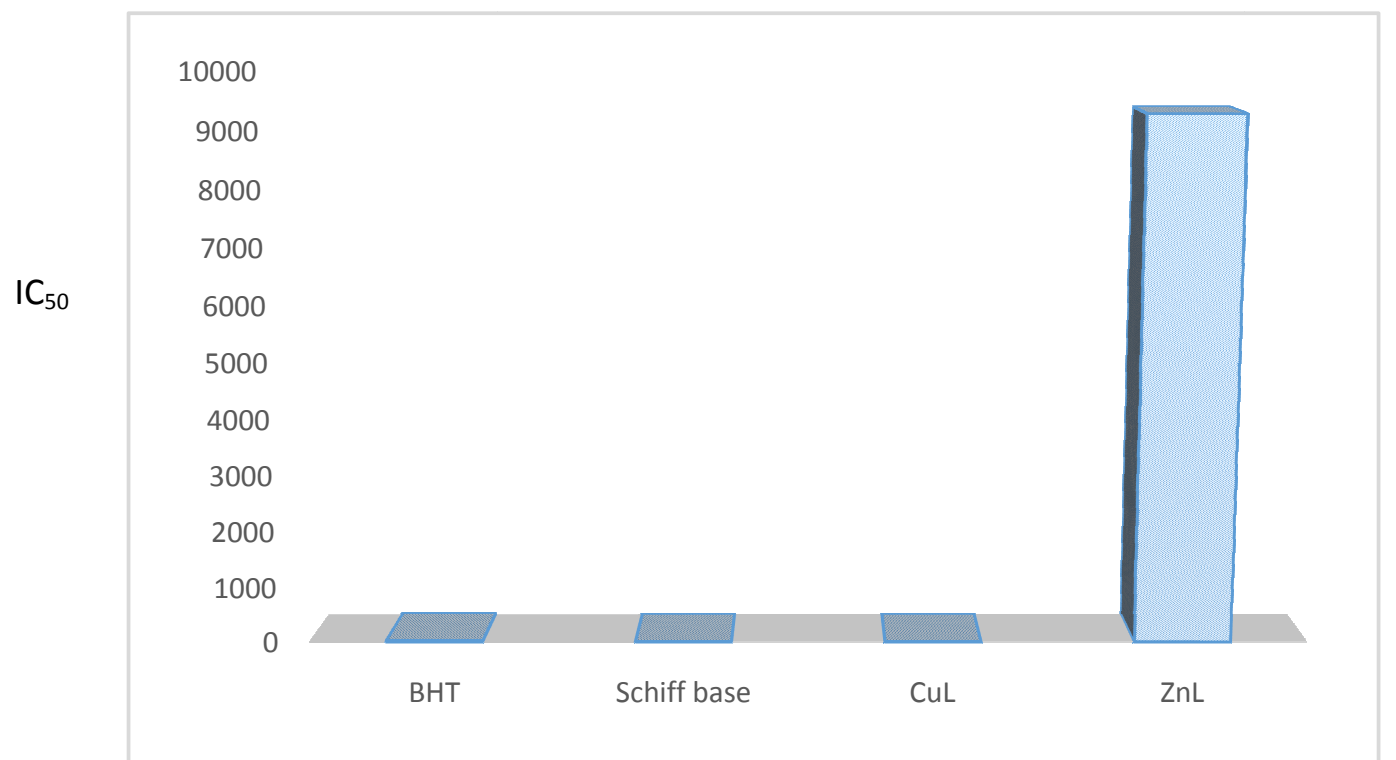

Figure 2: IC $_{50}$ of the Ligand and Metal (II) Complexes compared with BHT.

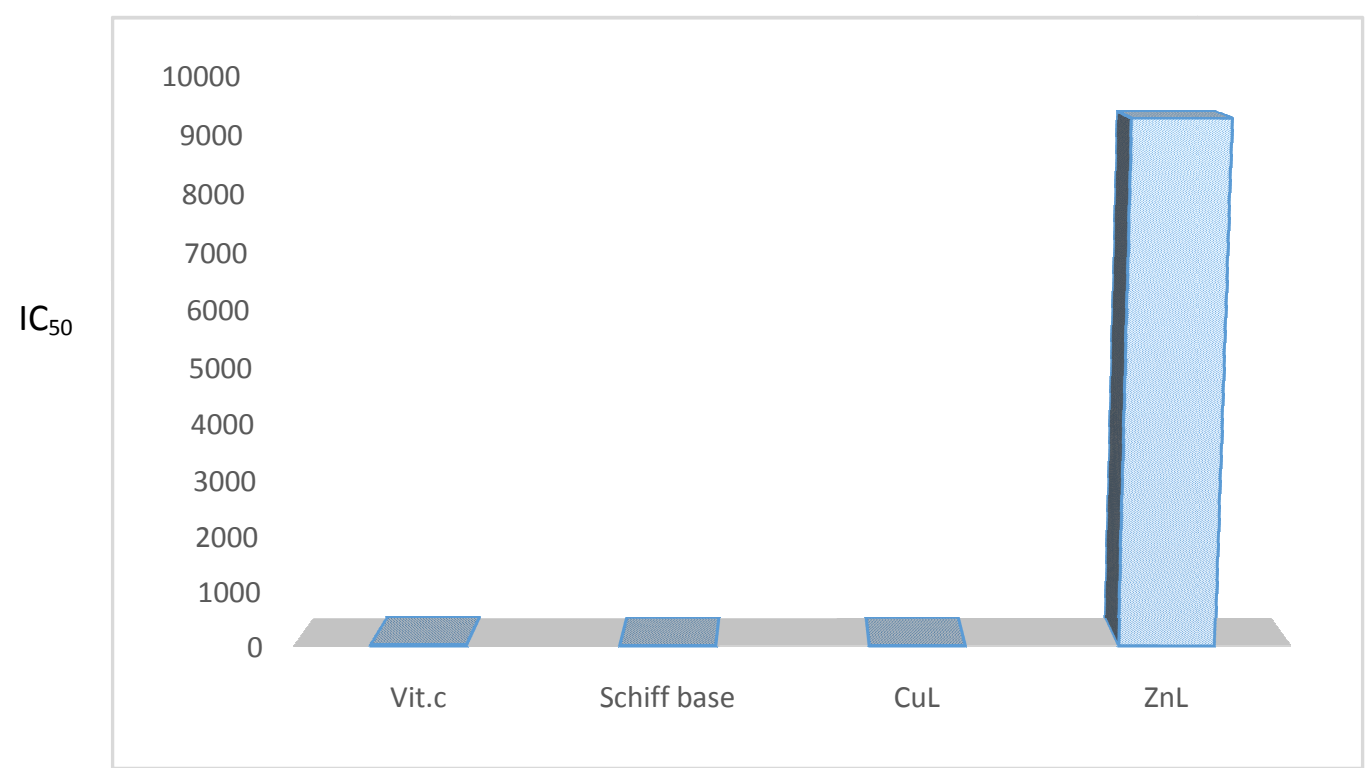

Fig 3: $\mathrm{IC}_{50}$ of the Ligand and Metal (II) Complexes compared with vitamin C

\section{CONCLUSION}

2-[(2-hydroxyphenyl) methylidene] hydrazine-1carboxamide.was synthesized by condensing salicylaldehyde and semicarbazide. Its metal (II) complexes of copper and zinc were synthesized. All the compounds were characterized. Antimicrobial and antioxidant studies showed that the compounds were active against some bacterial and fungal isolates. The ligand and its copper complex showed they can be used as radical scavenging agents while zinc complex do not possess antioxidant ability. From the analyses carried out, the molecular structure of the ligand and its metal (II) complexes are proposed in Fig. 4 and 5 respectively.

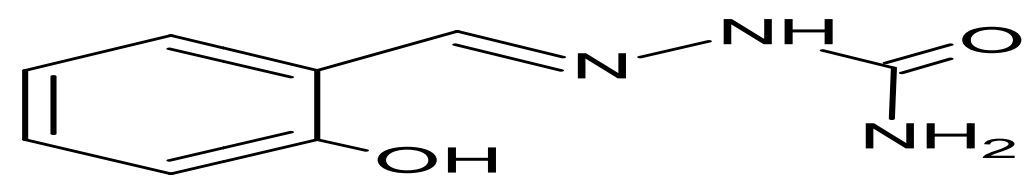

Figure 4: Proposed Molecular Structure of 2-[(2-hydroxyphenyl) methylidene]hydrazine-1carboxamide 


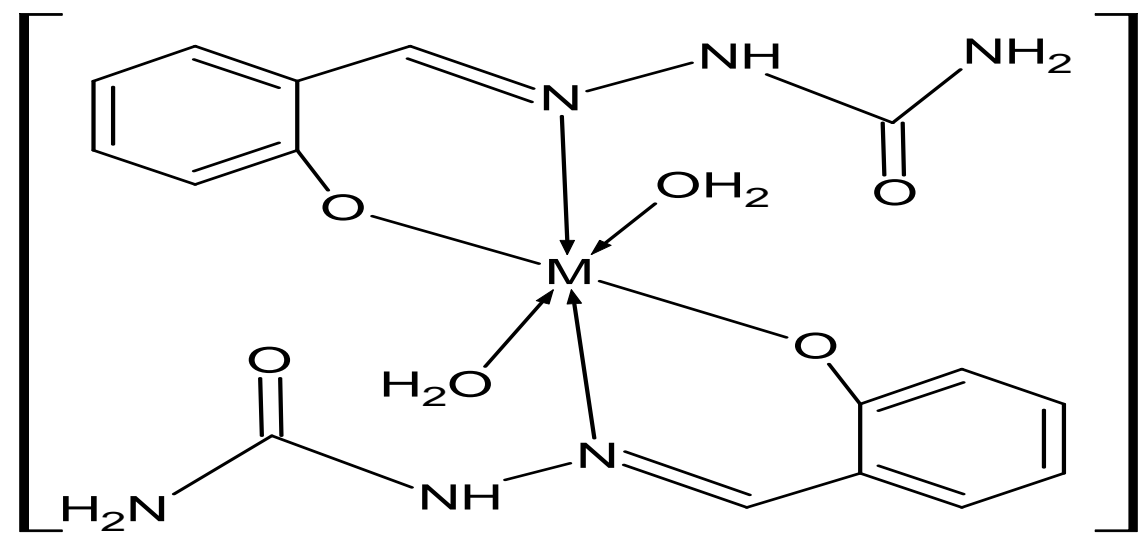

$\mathrm{M}=\mathrm{Cu}^{2+} \mathrm{Zn}^{2+}$

Fig. 5: Proposed Molecular structure of the Complexes

\section{RECOMMENDATIONS}

Further analyses like ${ }^{1} \mathrm{H} \mathrm{nmr}$ and crystallography may be carried out to fully establish the molecular structure of the compounds. Also, Toxicity test on the compounds may be carried out so as to establish possible application of the compounds in the pharmaceutical industry

\section{REFERENCES}

Angelici, R.J.(1971):" Synthesis and Techniques in Inorganic Chemistry", W.B Savders company, $2^{\text {nd }}$ edition, pp 115-125.

Beyeong Goo J., Chac-Pyong R., Hee- Nam C., KiHyun C, and Yohng-Koo C. (1996): Synthesis and Characterization of Schiff base derived from 2-hydroxy-1-naphthaldehyde and Aliphatic Diamines, Bull, Korean. Chem. Soc., Vol. 17, (8) pp 689-693 B

Chandra S,(2002); Chromium (III), Manganese (II), Iron (III), Cobalt (II), Nickel (II) and Copper (II) Complexes with a pentadentate 15membered new macrocyclic ligand, Transition Metal, Chem. 27: 196-199.

Chalapathi K, Ravi V. and Maddaiah G. P,(2010) Determination of $\mathrm{Cr}$ (III), Cu (II), Zn (II), Cd (II) and $\mathrm{Pb}$ (II) in Food Samples by FAAS after Preconcentration on Silica Gel Modified with 5-[2-hydroxybenzylideneamino]-2hydroxy benzoic acid, J. Chem. Pharm. Res. 2(2): 452-461.

Chandra S ,(2005); EPR, Mass, IR, Electronic and Magnetic Studies on Copper (II) Complexes of Semicarbazones and Thiosemicarbazones, Spectrachemica Acta A, 61: 269-275.

Cotton S, (2006); Lanthanide and Actinide Chemistry, Uppingham School, Uppingham, Rutland, UK: John Wiley \& Sons, Ltd.

Dharamraj, P. Viswanathanmurthi, and Natarajan,K. (2001) Trans. Met. Chem. 26, 105.

Fugu,, M.B. ,Ndahi, N.P., Paul, B.B. and Mustapha, A.N (2013): "Synthesis, Characterisation and Antimicrobial Studies of Some Vanillin Schiff base Metal(II) Complexes", Journal of

\section{Acknowledgements}

The authors are grateful to the Department of Pure and Industrial Chemistry and Department of Microbiology, Bayero University Kano, Nigeria for providing the facilities in this research.

\section{Chemical and Pharmaceutical} Research,vol.5(4),pp 22-28

Gary W. J. (1971): The Use of Conductivity Measurement in Organic Solvents for Characterization of Coordination Compounds, Chem. Review, 7(1), 81-122

Katsuki T,(1995) Catalytic Asymmetric Oxidations Using Optically Active (salen) Manganese (III) Complexes as Catalysts, Coord. Chem. Rev.;140: 189-214.

Kim, W. S;, Chung; K. I., Kim; S., Jeon, K. S., Kim; H. Y. Sung, Y. E. and Choi, Y. K. (1998): Bull Kor. Chem. Soc . 21,571- 576.

Morad F.M., Ei -ajaily M.M., Gweirif S.(2007): Preparation, Physical Characterization and Antibacterial Activity of Ni (II) Schiff Base Complex, Journal of Science and Its Applications, 1, 72-78.

Mounika K, Anupama B, Pragathi J, and Gyanakumari C,(2010): Synthesis, Characterization and Biological Activity of a Schiff Base Derived from 3-Ethoxy Salicylaldehyde and 2-Amino Benzoic acid and its Transition Metal Complexes, J. Sci. Res. 2 (3), 513-524.

Raman N., Joseph J., Sakthivel A. and Jeyamurugan R. (2009): Synthesis, structural Characterization and Antimicrobial Studies of Novel Schiff base Copper(II) Complexes, J. Chil. Chem. Soc. 54(4), 354-357

Raman N; YP Raja; A Kulandaisamy.(2001): Proc. Indian Acad. Sci. (Chem. Sci.),113(3), 183189.

Shinoda S, Tsukube H,(2002): Lanthanide Complexes in Molecular Recognition and Chirality Sensing of Biological Substrates. Chem. Rev. 102, 
Sharma, K., Swami, M., Singh, R.,Fahmi, N. and Singh, R.V. (2009): "Coordination chemistry of palladium(II) and platinum(II) complexes with bioactive Schiff bases: Synthetic, spectral ,and biocidal aspects", Russian Journal of Coordination Chemistry, Vol.35(2),pp 142-148

Sulekh, C, Smriti, R. and Ruchi V. (2012): Synthesis, Characterization and Biological Activities of Copper(II) Complexes with Semicarbazide and Thiosemicarbazide, Journal of Chemical and Pharmaceutical Research, 4(3), 16121618 www.depts.washington.edu Dielectric Constants of common solvents. Date assessed $23^{\text {rd }}$ June 2016

Youseef A,(2008): Reactions of Chromium and Molybdenum Carbonyls with bis(salicylaldehyde)-1,3-propylenediimine Schiff Base, J. Coord. Chem. 61: 816-822.

Ziyad A. T, Abdulaziz M. A, Khader A. A, Ahmed K. H. and Ari B. $F_{,}(2011)$ : Synthesis, Characterization, Biological Activity and Fluorescence Properties of bis(salicylaldehyde)-1,3-propylenediimine Schiff base Ligand and its Lanthanide Complexes, Spectrochimica Acta Part A 81 317-323. 